\title{
3. Uluslararası İslam ve Biyoetik Sempozyumu
}

3rd Islam and Bioethics International Conference

14-16 Nisan 2010, Antalya

EMINE GÖÇER

Arş. Gör., ÇUKUROVA Ü. İLAHIYAT FAKÜLTESİ

eminegocer3000@gmail.com

İlki 2001 y1lında Haifa Üniversitesi tarafindan İsrail'de, ikincisi ise 2006 yılında Pennsylvania State Üniversitesi tarafindan Amerika'da gerçekleştirilen sempozyumlar dizisinin sonuncusu, 14-16 Nisan 2010 tarihinde Ankara ve Haifa Üniversitesi'nin iş birliği ile 3. Uluslararası İslam ve Biyoetik Sempozyumu adıyla Antalya'da düzenlenmiştir

Sempozyumun açılış konuşmasını yapan Ankara Üniversitesi'nden Prof. Dr. Yasemin Oğuz toplantıya katılanlar hakkında bilgi vererek Türkiye'nin ev sahipliğini yaptığı bu toplantıda İsrail, Malezya, İtalya, Birleşik Arap Emirlikleri, Amerika, Nijerya, İngiltere, Suudi Arabistan, Hindistan gibi dört farklı kıtadan, 17 ülkeden, 70'in üzerinde katılımcının bir araya geldiğini dile getirdi. Konuşmasında günümüzde biyoetiğin önemi üzerinde duran Oğuz, UNESCO'nun biyoetiğin tıp fakültelerine bir bölüm olarak yerleşmesinde büyük katkısı olduğu üzerinde durarak, bu toplantıda bulunan UNESCO Biyoetik Başkanı olan Prof. Dr. Amnon Carmi'nin de toplantının uluslar arası düzenleme kurulunda bulunduğunu ifade etti.

Üç gün devam eden sempozyumda on oturumda 36 tebliğ ve 9 poster sunuldu. 14 Nisan 2010 Çarşamba günü Prof. Dr. Vardit Rispler-Chaim'in başkanlığında gerçekleştirilen toplantının ilk oturumunda Türkiye'nin Vatikan Büyükelçisi Prof. Dr. Kenan Gürsoy "Belief Systems and Ethics," (İnanç Sistemleri ve Ahlak) adlı tebliğini sundu. Gürsoy, tebliğinde teist ve teist olmayan dinlerin kendilerine evrensel ahlaki değerleri ilke edinmeleri gerektiğini ve bunun da ne pozitivist bakışa sahip insanların dinden uzaklaşarak aydınlığa kavuşacağını savunmakla ne de belirli bir dinin fanatikliğini yapmakla elde edilebileceğini ileri sürdü. Dünya barışı açısından dinler arası alanda ahlaki birliktelik sağlanabilmesi için ahlakın ötekini de içine alacak şekilde oluşturulması gerektiğini, farklı gelenek ve kültürler arasında kalmış tikel olan şeylerden ziyade genel 
olanı soyutlayarak 'birlik hakikatine' ulaşmanın ana gaye olduğunu dile getirdi. Gürsoy, birlik hakikatine ise ne Platon'nun insanın determinist yapıda olduğunu ileri sürmesiyle ne de J. P. Sartre'ın insanın mutlak özgür bir doğaya sahip olduğunu ileri sürmesiyle ulaşılabileceğini belirtti. Burada insanın Platon ve Sartre'1 aşarak hem biyolojik bir yapıya hem de fitrata uygun bilinçliliğe sahip insan olarak değerlendirilmesi gerektiğini vurgulayarak, 'bilinçli gayelilik' kavramsallaştırması üzerinde durulması gerektiğini ifade etti.

Prof. Dr. Amnon Carmi’nin başkanlığında düzenlenen oturumda Prof. Dr. Hayrani Altıntaş "Ethical Responsibility in Islam and Bioethics," (İslam ve Biyoetikte Ahlaki Sorumluluk) adlı tebliği sundu. Altıntaş, tebliğinde İslamî değerler bazında insanın görevinin ne olması gerektiğini sorgularken insan zihninin bu bilince ulaşabilmesi için aklın emri ile mi yoksa vahyin emri ile mi ulaşması gerektiği üzerinde durdu. Altıntaş, aklın saf halde öze ulaşabilmesi mümkünken insanın yanılmaz bir şuura sahip olmadığını vurgulayarak yanılmaz olanın ancak aşkın değerlere sahip olan Tanrı olduğunu dile getirdi. Bu bağlamda her şeyi yapabilme imkânına sahip insanın tıp, biyoloji, genetik alanındaki gelişmeler sayesinde ellerine verilen imkânı kullanma hakkına sahip olup olmadığının biyoetik ve İslam ahlakı açısından sorgulanması gerektiği üzerinde durdu.

Başkanlığını Doç. Dr. Müfit Selim Saruhan'ın yaptı̆̆ bir başka oturumda Doç. Dr. Mahmut Ay "Theo-Ethical Admissibility and Limitations of Tampering with Human Nature in Islamic Theology," (Kelam Alanında İnsan Doğasına Müdahalenin Dini-Etik Açıdan Geçerlilik ve Sınırları) adlı tebliği sundu. Ay, tebliğinde insan doğasına müdahalenin sınırlarını belirleme açısından insan özgürlüğünü üç tür teolojik yaklaşıma göre ele alınabileceğini ifade etmiştir. Bunlardan ilki dogmatik teolojik yaklaşım, ikincisi rasyonel teolojik yaklaşım, diğeri ise mistik teolojik yaklaşımdır. Ay, insan varlığının Tanrının bilgi, irade ve kudretinin bir sonucu olarak ortaya çıkan Tanrının bir parçası mı yoksa özgür bir varlık mı olduğu sorusuna verilecek cevabın insan doğasına müdahalenin sınırlılıkları içerisinde belirleneceğini ileri sürdü. Rasyonel teolojik yaklaşım üzerine vurgu yapan Ay, insanın yaratma ve özgürlük kavramlarına ancak rasyonel teolojik bakış açısıyla bakıldığında insan doğası üzerine müdahalenin ölçü ve dengesine ulaşılabileceğini ileri sürdü. İnsan doğasına müdahalenin adaletin gözetilmesi, sağduyunun sağlanması ve kaosa sebebiyet verilmemesi koşuluyla izin verilebileceğini dile getirdi. Ölçü ve ilkelerin belirleyicisi olarak insanın genel kaynak olarak aklı, özel kaynak olarak ise vahyi temel alması gerektiğini de ekledi. 
15 Nisan 2010 Perşembe günü başkanlığını Prof. Dr. Berna Arda'nın gerçekleştirdiği günün ilk oturumunda Prof. Dr. Şahin Filiz "The Place of Bioethics Principles in Islamic Ethics," (İslam Ahlakında Biyoetik İlkelerin Yeri) adlı tebliğini sundu. İslam'ın biyoetik meseleler açısından var olan problemler hakkında tek bir bakışa sahip olmadığını ve bu çeşitliliğin ise farklı fikıh ekollerinden, farklı mezheplerden ve kültürel farklılaşmalardan kaynaklandığını öne sürdü. Tıp etiği ile İslam hukuku arasında bir çelişki meydana getirdiğinden söz ederek İslam Ahlak Felsefesi ile İslam hukuku arasında bir uzlaşım sağlanması gerektiğinin zaruret olduğunu ileri sürdü. Bundan böyle İslam ahlakını İslam hukukuna gönderme yaparak oluşturmak yerine İslam Ahlak Felsefesi ya da teorik bir ahlak üretilmesi gerektiği üzerinde durdu. Şahin, İslam hukukunun doğum kontrolü, kürtaj, organ nakli, kopyalama, ötenazi gibi biyoetiğin problemli temel meseleleri hakkında kısa süreli, bölgesel ve bağlamsal çözüm önerileri neticesinde fetvalarının yetersiz ve çelişkiler içerdiğini vurgulayarak İslam felsefesinin bir parçası olarak İslam biyoetiğinin yapılandırılması halinde gelecekte var olacak meseleler üzerinde teorik bir çerçeve oluşturabileceğini dile getirdi.

Başkanlığını Prof. Dr. Hayrani Altıntaş'ın yaptığı oturumda Dr. Abdul Rezzak Abdul Mecid Alora "Assisted Reproduction Technology (ART): The Islamic Law Perspective," (Yardımcı Üreme Tekniği: İslam Hukuku Açısından) adlı tebliğini sundu. Alora, yardımcı üreme tekniklerine başvurulmasının sebebi olarak bilinen kısırlığa İslam'ın nasıl baktığı üzerinde durdu. Öncelikle kısırlığın bir hastalık olup olmadığını sorguladı. Erkek ya da kadından kaynaklanan kısırlığın dışında hiçbir nedene bağlanamayan kısırlıkların sadece bir hastalık olarak kabul edilebileceğini ileri sürdü. Bunun yanı sıra yardımcı üreme tekniklerinin kısır olmayan çiftler tarafından uygulanmasının sorgulanması gerektiği ve bu tür durumların birçok risk içerdiğini dile getirdi. Şeriata göre tek annelik ve babalığın caiz görülmediğini ve bir kişinin evlenmemeyi seçmesinin çocuk sahibi olmamayı da seçmesi anlamına geldiğini ileri sürdü. Cinsiyet tayininin zaruri durumlar dışında Tanrı'nın iradesine bırakılması gerektiğine değindi. Ayrıca sperm, yumurta ve embriyon bağışı üzerinde duran Alora, ensest ilişkilere sebep olacağından İslam hukukuna hiçbir şekilde bu tür ilişkilere izin vermediğinin altını çizdi. Burada dikkat edilmesi gereken bir diğer hususun ise İslam hukuku açısından sperm, yumurta veya embriyon bağışının zina olarak kabul edilmemesi ve bunun zinadan ziyade ancak nesebin yozlaşması olarak görülmesi gerektiğine dikkat çekti. 
16 Nisan 2010 Cuma günü başkanlığını Prof. Dr. Nouzha Guessous Idrissi’nin gerçekleştirdiği oturumda Dr. Aasim I. Padela, "Brain Death: Epistemologic and Doctrinal Challenges for Modern Islamic Bioethics," (Beyin Ölümü: Modern İslam Biyoetiği Açısından Epistemolojik ve Kuramsal Tartışmalar) adlı tebliğini sundu. Padela, İslam'ın beyin ölümü hakkında neler söylediği üzerinde yoğunlaşarak günümüzde kabul edilen beyin ölümü tanımının Batının getirdiği tanımlama olarak kabul edilmesi gerektiğini vurguladı. Bu bağlamda batı rasyonel felsefesine göre insanı akıllı bir canlı olarak görmekle insanlığın ayırt edici özelliğinin düşünme yeteneği ve benliğinin farkında olmak olduğunu dile getirdi. Buradan yola çıkarak tıp bilimi düşüncenin merkezini, beyin olarak belirlediği için şayet beyin, faaliyetine ara verirse bu durumun kolaylıkla bir ölüm tanımı olarak anlaşılabileceği üzerinde durdu. Padela, sadece bedene indirgenen bir ölüm tanımının İslami gelenekle çeliştiğini dile getirdi. Aynı zamanda İslami gelenekte ruh-beden dualizminden bahsedildiğini ve insanlığın ayırt edici özelliği olarak düşünmenin beyinde gerçekleşmesinden ziyade ruhta gerçekleştiğini dile getirdi. Beynin, ruhun bir aracı olarak görüldüğünü bu sebeple de ölümün bedenden ziyade ruhun bir unsuru olduğunu ifade etti. Padela, bu bağlamda şu sorulara cevap aranması gerektiğini vurguladı. İslam hukukunda beyin ölümü geçerli mi, geçerli ise ruh İslam dinine göre beynin içinde mi yer alır? Bilimsel kriterlere göre ölü ve kişi tanımlandığında İslam hukukunun kaynakları açısından bu tanımlara ne tür çıkarımlar sunulur?

Son y1llarda sıkça gündeme gelen böylesine önemli bir konunun Türkiye'de uluslararası düzeyde ilk defa bu sempozyumda tartışılması ve kısmen de olsa çözüm önerilerinin dile getirilmesi biyoetik çalışmalarına önemli bir katkı olarak ifade edilebilir. Özellikle de tebliğlerin basılmasından sonra biyoetikle ilgili literatür arasında önemli bir kaynak olarak yer alacaktır. Üç gün süren sempozyum boyunca en önemli sorun olarak dile getirilen biyoteknolojik ve biyomedikal gelişmelerle yaklaşık son yarım asırdır karşılaşan İslam ülkelerinin bu gelişmelere karşı ürettikleri çözümlerin yetersiz kalmasıydı. Yetersiz kalmasının sebebi olarak da biyoetik alanda var olan ahlaki problemlere karşı girişilen birçok farklı içtihat hareketleri ve fetva kurumlarının koyduğu hükümlerin kazuistik yapıda olması gösterilmiştir. Bu açıdan disiplinlerarası çalışmaların gerekliliği vurgulanmıştır. Kanaatimizce böylesine kapsamlı bir sempozyumun benzerlerinin önümüzdeki dönemde de sıklıkla düzenlenmesi bilim dünyasına önemli kazanımlar sağlayacaktır. 